\title{
Serum Cytokines in Erythema Nodosum Leprosum Versus Non-Reactional Leprosy: A Systematic Review and Meta-analysis
}

\author{
Mia Katrina R. Gervasio, ${ }^{1}$ Felix Paolo J. Lizarondo ${ }^{1}$ and Belen L. Dofitas ${ }^{2}$ \\ ${ }^{1}$ Section of Dermatology, Department of Medicine, Philippine General Hospital, Univerity of the Philippines Manila \\ ${ }^{2}$ Section of Dermatology, Department of Medicine, College of Medicine and Philippine General Hospital, Univerity of the Philippines Manila
}

\begin{abstract}
Background. Erythema nodosum leprosum is an immune-mediated complication of leprosy whose underlying mechanism has not yet been fully elucidated, making management difficult.
\end{abstract}

Objectives. To determine the serum cytokine profile of ENL compared to non-reactional leprosy states.

Methods. An open literature search was performed using MEDLINE, Cochrane Library, TRIP and HERDIN electronic databases using the keywords ("cytokines" or "inflammatory mediators") and ("erythema nodosum leprosum" or "ENL") and ("leprosy" or "lepra"). Studies were selected by two independent review authors. Risk of bias was assessed using the Newcastle-Ottawa Scale and statistical analysis was performed using RevMan 5.3 software.

Results. Eight cross-sectional studies with 197 participants were included. Meta-analysis showed that both serum IL-17 and serum IFN- $\gamma$ were significantly decreased (Z 2.39, $p=0.02$ and Z 2.74, $p=0.01$, respectively) in ENL compared to non-reactional states. However, for IL-1 $\beta$, IL-6, IL-10, IL-22, TNF- $\alpha$ and TGF- $\beta$, no significant differences were found between the two groups.

Conlusion. ENL appears to be an exacerbation of the Th2 cytokine response seen in the lepromatous pole of leprosy. However, despite pooling of data, sample sizes remain small resulting in significant heterogeneity. Future studies involving large sample sizes and investigating a wider range of cytokines are encouraged.

Key Words: serum cytokines, erythema nodosum leprosum, lepra reaction

\section{INTRODUCTION}

E-poster presented at the $40^{\text {th }}$ Annual Convention of the Philippine Dermatological Society, November 8-10, 2017, EDSA Shangri-La Hotel, Mandaluyong City, Philippines.

Corresponding author: Mia Katrina R. Gervasio, MD

Section of Dermatology

Department of Medicine

Philippine General Hospital

Univerity of the Philippines Manila

Taft Avenue, Manila 1000, Philippines

Telephone: +6325548400 local 5105

Email:mrgervasio@up.edu.ph
Leprosy is a chronic granulomatous infection caused by the obligate intracellular organism Mycobacterium leprae, which primarily affects the skin and peripheral nerves. ${ }^{1,2}$ It is a spectral disease, presenting with a range of clinical manifestations that correlate with an individual's immune response to the pathogen. ${ }^{3}$ Using the RidleyJopling classification, the spectrum is divided into five different groups: tuberculoid (TT), borderline tuberculoid $(\mathrm{BT})$, borderline $(\mathrm{BB})$, borderline lepromatous $(\mathrm{BL})$ and lepromatous (LL). ${ }^{4,5}$

Those in the tuberculoid pole exhibit a strong cellmediated immune response that restricts the growth of the organism thereby manifesting clinically with fewer lesions and lower bacterial load. This cell-mediated immune response is characterized by the predominance of CD4+ (helper/inducer) $\mathrm{T}$ cells, which produce a Th1 cytokine pattern with interleukin 2 (IL-2) and interferon gamma 
(IFN- $\gamma)$. The abundance of IL- 2 and IFN- $\gamma$ contributes to a more resistant state, as IL-2 induces clonal expansion of $\mathrm{CD} 4+\mathrm{T}$ cells, while IFN- $\gamma$ stimulates macrophage activation releasing tumor necrosis factor- $\alpha(\mathrm{TNF}-\alpha)$ and enhanced production of reactive oxygen species, thus interfering with the growth of mycobacteria (Figure 1) $)^{3,6}$

In contrast to the tuberculoid pole, the lepromatous pole exhibits a humoral response predominated by CD8+ (suppressor/cytotoxic) $\mathrm{T}$ cells which stimulates a Th2 cytokine pattern producing interleukin 4 (IL-4), interleukin 5 (IL-5), and interleukin 10 (IL-10). Both IL-4 and IL-10 have been found to have negative immunoregulatory effects on cell-mediated immunity, blocking $\mathrm{T}$ cell proliferation as well as the release of Th1 cytokines. Thus, the lepromatous pole exhibits a higher susceptibility to Mycobacterium leprae infection, presenting clinically with more numerous skin lesions and a higher bacterial index (Figure 1).,

Aside from the classic Th1 and Th2 cell lineages, additional subsets of Th17 and Treg have been discovered. Th17 play a role in pathogen clearance, producing interleukin 17 (IL-17) and interleukin 22 (IL-22) that lead to tissue inflammation and destruction. Interleukin 17 has been shown to bind cell surface receptors stimulating a Th1 response, and its sustained expression is influenced by interleukin$1 \beta$ (IL-1 $\beta$ ). In contrast, Treg cells exhibit an inhibitory role in the regulation of inflammation. Differentiation towards a Th17 lineage depends on the action of transforming growth factor- $\beta$ (TGF- $\beta$ ) in combination with interleukin 6 (IL-6), with Treg cells exerting a suppressive effect on Th17 differentiation depending on the relative levels of both TGF- $\beta$ and IL-6 (Figure 1). ${ }^{7,8}$

The immune response to $M$. leprae may also cause two types of immune-mediated complications known as lepra reactions. Reversal reaction, or type 1 lepra reaction, presents as acute inflammation of the skin and nerves and occurs mostly in patients with borderline leprosy (BT, BB and BL). Erythema nodosum leprosum (ENL), or type 2 lepra reaction, presents with crops of new erythematous painful nodules usually on the extremities, which may be accompanied by other symptoms such as fever and swelling of the nerves, eyes, joints, testes, and lymph nodes. ENL may be intermittent or chronic and may persist over several years after completion of multi-drug therapy. The reaction only occurs in people with borderline lepromatous (BL) or lepromatous (LL) leprosy and the prevalence may be as high as $50 \%$ in patients with LL. ${ }^{5,9}$ Major risk factors which may lead to the development of ENL include a high bacterial index and age below 40 years. ${ }^{10}$

While the immunologic mechanisms underlying the clinical spectrum of leprosy have been extensively studied, the precipitating factors, as well as the immune responses that govern erythema nodosum leprosum remain unclear. ${ }^{9}$ To date, there are no published meta-analyses on the serum cytokine levels in ENL. For most patients, this condition is

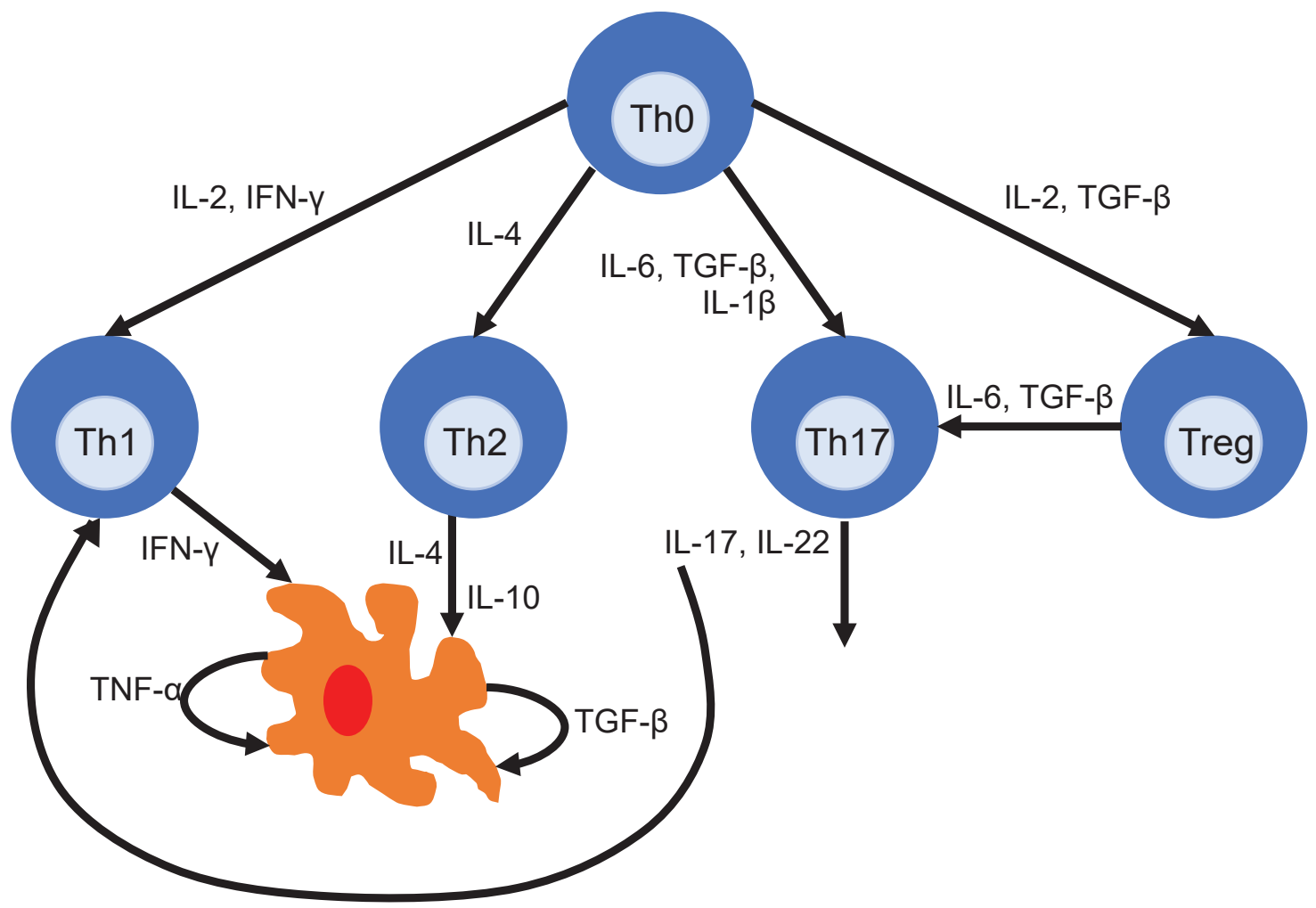

Figure 1. Cytokines in leprosy. Upon presentation of foreign antigens, naive T cells (Th0) can differentiate into Th1, Th2, Th17 and Treg cells whose stimulation or suppression depends on a number of different cytokines. 
usually chronic and relapsing, with adverse effects on both the physical well-being of the patient and on their quality of life. Thus, investigating the key cytokines involved in ENL versus non-reactional states may shed light on its pathophysiology and provide opportunities to improve approaches to its therapeutic management.

This study aimed to determine the serum cytokine profile of ENL compared to non-reactional leprosy states.

\section{METHODS}

\section{A. Criteria for inclusion of studies}

\section{Types of studies}

All observational studies measuring serum cytokine levels in erythema nodosum leprosum compared to nonreactional leprosy states were included. Articles were excluded if no data was available for analysis and if patients were started on MDT treatment or other immunomodulating drugs prior to sampling.

\section{Types of participants}

Individuals diagnosed with ENL and presenting with its distinct clinical features were included. ENL is an inflammatory reaction characterized by the development of erythematous, tender crops of subcutaneous nodules, which may be accompanied by inflammation of the nerves, joints, iris, testes, fingers, and toes, and may present with fever, edema, and lymphadenopathy. ${ }^{5}$

As a comparator, individuals diagnosed with nonreactional leprosy, whether borderline tuberculoid, lepromatous, or multibacillary leprosy without lepra reaction were included. Leprosy is defined as a chronic granulomatous infection caused by Mycobacterium leprae whose clinical manifestation is dependent upon the host's immune response., ${ }^{2,11,1}$ Diagnosis and classification is dependent on clinical presentation and supported by slit skin smear and skin biopsy results. ${ }^{2}$

\section{Types of outcome measures}

The primary outcome measure was the difference in the mean serum cytokine levels between patients with ENL and patients with non-reactional leprosy.

\section{B. Search methods for identification of studies}

An open literature search was performed using MEDLINE, Cochrane Library, TRIP and HERDIN electronic databases. All articles from 1 January 1950 until 30 August 2016 were screened using the medical subject headings ("cytokines" or "inflammatory mediators") and ("erythema nodosum leprosum" or "ENL") and ("leprosy" or "lepra") to identify potentially relevant articles. Other resources such as Google scholar were also searched, and the reference lists of relevant articles were screened for other related studies or relevant reviews. There were no language restrictions while searching for publications since all relevant articles were published in English.

\section{Data collection and analysis}

\section{Selection of studies}

Two independent authors perused the titles and abstracts obtained from the searches. Upon selection, all articles were compiled and a full text review was done. Articles that did not fit the inclusion criteria, as well as duplicate articles were excluded. If the authors were unclear regarding the inclusion of an article, the issue was resolved through discussion between the authors. Referral to a third author for the resolution of disagreements between the two independent authors was not necessary for this study.

\section{Data extraction and management}

One author extracted the data using a standard data extraction form (Appendix A), which included the author, year, type of study, country, number of participants, age and sex, cytokines measured, and the method of measurement. The second author checked the data and any discrepancies were discussed and settled between the two authors. One author entered all relevant data into Review Manager 5.3 software for analysis. Neither of the authors were blinded to the names of trial authors, journals or institutions.

\section{Quality assessment of included studies}

The evaluation of the quality of the included studies was done using the Newcastle-Ottawa Scale (NOS) for non-randomized studies in meta-analysis. A cumulative score of six or higher for each included study was considered good quality. ${ }^{12} \mathrm{~A}$ tabulation of the information is recorded in the risk of bias table.

\section{Dealing with missing data}

In the event of missing data such as standard deviations, the authors of the selected studies were contacted to provide missing statistics. If there was no response from the authors, only the available data was analyzed or replacement values were computed in accordance with the Cochrane guidelines. ${ }^{13}$

\section{Assessment of heterogeneity}

To quantify the heterogeneity of the included studies, $\mathrm{I}^{2}$ statistic was used.

\section{Assessment of reporting biases}

The assessment of reporting biases using funnel plots was not performed for this analysis since there were less than ten aggregate studies.

\section{Data synthesis}

The effect size representing the difference in mean serum inflammatory marker levels between patients in reactional and non-reactional states were calculated using 
the weighted mean difference (WMD). The respective 95\% confidence intervals $(\mathrm{CI})$ were also reported. For studies that did not report the mean, the median was used for analysis. If the studies provided the median interquartile range, the values were converted to standard deviation (SD). For studies wherein the standard deviation was unavailable, we assumed that the values lay within two SDs of the mean. The weighted mean differences were analyzed using a random-effects model to account for within- and between-study variance. The test for overall effect using $Z$ score was considered significant if the $p$-value was $<0.05$. All statistical analyses were performed using Review Manager 5.3 software.

\section{RESULTS}

\section{A. Description of studies}

\section{Results of the search}

The study selection process is outlined in Figure 2. Our initial search yielded 1134 articles, of which 1111 articles were excluded based on initial screening of titles and abstracts. Twenty-three potentially relevant articles underwent full text review. Fourteen (14) articles were excluded based on desired outcome measures and exclusion criteria. Of the remaining 9 relevant articles, 1 article was excluded for overlapping data with an included article. All 8 remaining studies were then included in the analysis. No similar meta-analyses were found.

\section{Included studies}

We included eight studies with a total of 197 participants (84 patients with ENL) in this review, the characteristics of which are summarized in Appendix A. All studies were crosssectional studies published between 1993 and 2016.

\section{Sample size}

The study populations had total participants ranging between 45 and 275, with the size of the involved populations ranging between 17 and 50 participants.

\section{Setting}

Three studies were conducted in single centers in Egypt, while six studies were conducted in single centers in India.

\section{Participants}

Only two studies reported the age range of participants for the ENL group, while only one study reported the mean age of participants for the non-reactional (NR) group. Similarly, only two studies reported the number of male and female participants for the ENL group, while only one study reported the mean age of participants for the NR group. The rest of the studies did not publish any data regarding the age and sex of the participants. All participants were newly diagnosed cases of leprosy - whether in ENL or nonreactional states - who have not yet received prior treatment with multidrug therapy or any immunomodulating drugs.

\section{Outcome detection}

The primary outcome of serum cytokine levels was reported in all 8 studies. Three studies reported on the levels of interleukin-1 $\beta$ (IL-1 $\beta),{ }^{14-16}$ two studies reported on the levels of interleukin-6 (IL-6), ${ }^{7,16}$ three studies reported on the levels of interleukin-10 (IL-10), ${ }^{14,15,17}$ four studies reported on the levels of interleukin-17 (IL-17), ${ }^{7,17-19}$ two studies reported on the levels of interleukin-22 (IL-22), ${ }^{7,17}$ three studies reported on the levels of tumor necrosis factor- $\alpha$ (TNF- $\alpha),{ }^{14,15,20}$ two studies reported on the levels of transforming growth factor- $\beta$ (TGF- $\beta$ ), 7,17 and three studies reported on the levels of interferon- $\gamma($ IFN- $\gamma){ }^{14-16}$

\section{Excluded studies}

We excluded a total of 15 articles following full text review. Six studies were excluded due to the absence of a comparator group. ${ }^{21-26}$ Four studies were excluded since the participants involved a mix of both untreated and priortreated populations. ${ }^{27-30}$ One study was excluded because serum cytokines were not measured. ${ }^{31}$ Three studies were excluded due to lack of pertinent data. ${ }^{32-34}$ Finally, one article was excluded due to overlapping data with an included study. ${ }^{35}$

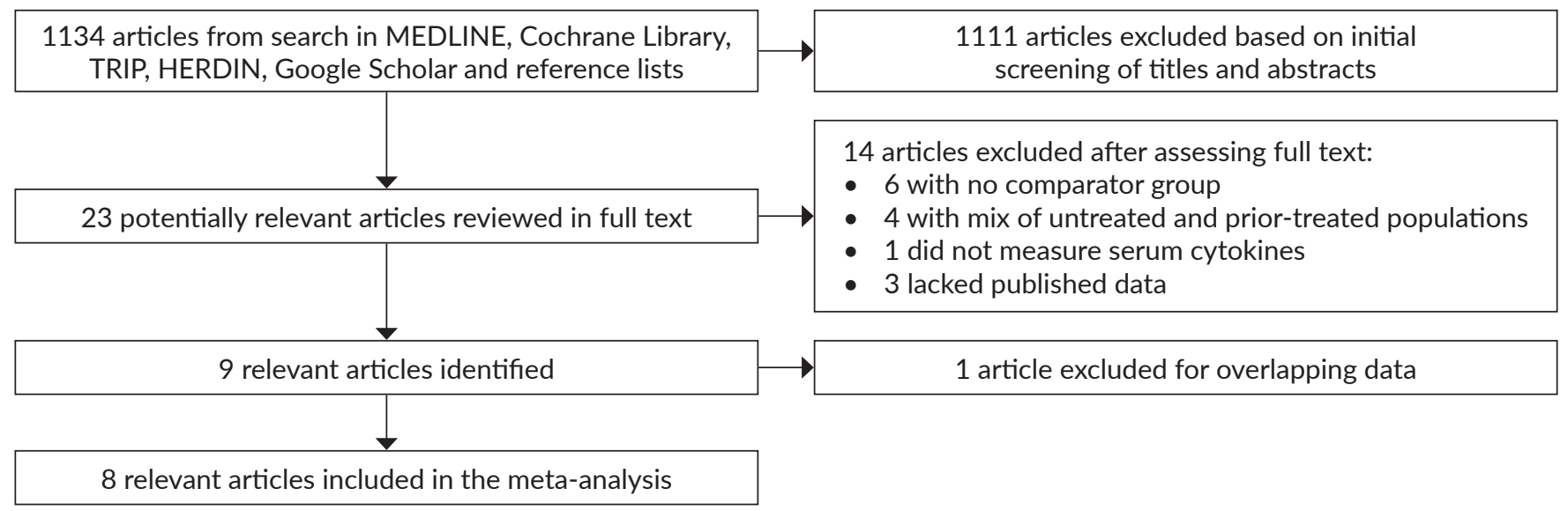

Figure 2. Flow diagram of study selection. 


\section{Risk of bias in included studies}

The Newcastle-Ottawa quality assessment scale of observational studies was used to evaluate the included studies with regard to their risk of bias.

\section{Selection}

For all included studies, representativeness of the sample was affected since sampling was done in a hospital or single institutional setting, rather than in the community and none of the studies indicated the justification for their respective sample sizes. Since sampling was done at a single time point, the response rate is satisfactory, and all measurement tools used to evaluate the sample were validated.

\section{Comparability}

All studies included untreated patients for both ENL and NR populations. Seven out of eight studies also matched the groups in terms of age and sex.

\section{Exposure or Outcome}

As for the assessment of the outcome, none of the studies reported blinding of the assessors. However, serum cytokine concentrations can be measured objectively, blinding is not necessary and does not influence the risk of bias for this analysis. Eight of the nine included studies performed statistical analysis, while one study only published the data without analysis.

\section{B. Data and pooled analyses}

\section{Interleukin-1 $\beta$}

The weighted mean difference (WMD) for studies analyzing IL-1 $\beta$ was 25.91 (95\% CI -1.69-53.51) with a $Z$ score of 1.84 and a $p$-value of 0.07 , indicating that there was no significant difference in serum IL- $1 \beta$ between patients with ENL versus NR leprosy. The pooled studies however showed a substantial level of heterogeneity with $\mathrm{I}^{2}=73 \%$ (Figure 3).

\section{Interleukin-6}

Only two studies analyzed serum IL-6 levels between patients with ENL and NR leprosy. Figure 4 shows a combined WMD of 132.18 (95\% CI -506.01-770.36) and a $\mathrm{Z}$ score of 0.41 corresponding to a $p$-value of 0.68 indicating that there was no significant difference in IL-6 concentrations between the two groups. Heterogeneity between studies was considerable, with $\mathrm{I}^{2}=89 \%$.

\section{Interleukin-10}

Combining serum IL-10 levels resulted in a nonsignificant WMD (11.70, 95\% CI -9.70-33.11, $Z=1.07$, $p=0.28)$ between patients with ENL and NR leprosy (Figure 5). There was also considerable heterogeneity between pooled studies with $\mathrm{I}^{2}=80 \%$.



Figure 3. Forest plot for interleukin-1 $\beta$ (IL-1) showing the weighted mean differences (WMDs) and 95\% confidence intervals (Cls) of individual studies and pooled WMDs and 95\% Cls in patients with erythema nodosum leprosum (ENL) and non-reactional (NR) leprosy using a random-effects model.

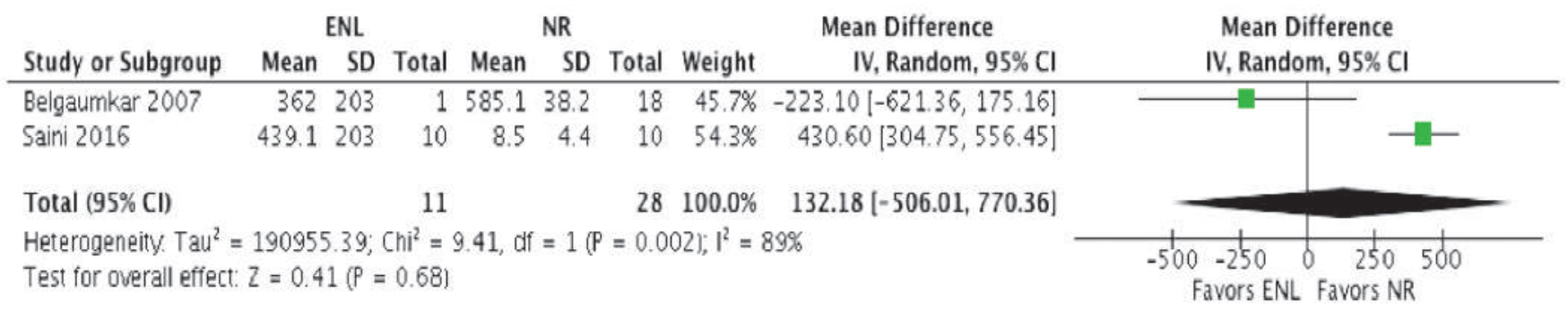

Figure 4. Forest plot for interleukin-6 (IL-6) showing the weighted mean differences (WMDs) and 95\% confidence intervals (Cls) of individual studies and pooled WMDs and $95 \% \mathrm{Cls}$ in patients with erythema nodosum leprosum (ENL) and non-reactional (NR) leprosy using a random-effects model. 


\section{Interleukin-17}

The search yielded four studies investigating the levels of IL-17, with a combined WMD of 153.19 (95\% CI 27.53-278.85) and an overall $Z$ score of $2.39(p=0.02)$ indicating significantly lower levels of IL-17 in erythema nodosum leprosum compared to non-reactional leprosy. The heterogeneity between studies however was considerable at $\mathrm{I}^{2}$ of $97 \%$ (Figure 6).

\section{Interleukin-22}

Comparison of the IL-22 levels of the two groups in Figure 7 showed a WMD of -247.77 (95\% CI -812.61-
$317.07)$ with a $Z$ score of 0.86 and a $p$-value of 0.39 indicating a non-significant difference in serum IL-22. Heterogeneity between studies was also considerable, with $\mathrm{I}^{2}=99 \%$.

\section{Tumor necrosis factor- $\alpha$}

Three studies analyzed serum TNF- $\alpha$ levels between patients with ENL and NR leprosy. Figure 8 shows a combined WMD of 7.89 (95\% CI -1.18-16.96) and a Z score of 1.70 corresponding to a $p$-value of 0.09 indicating a non-significant difference in serum TNF- $\alpha$ concentrations between the two groups. Heterogeneity between studies were negligible, with $\mathrm{I}^{2}=21 \%$.

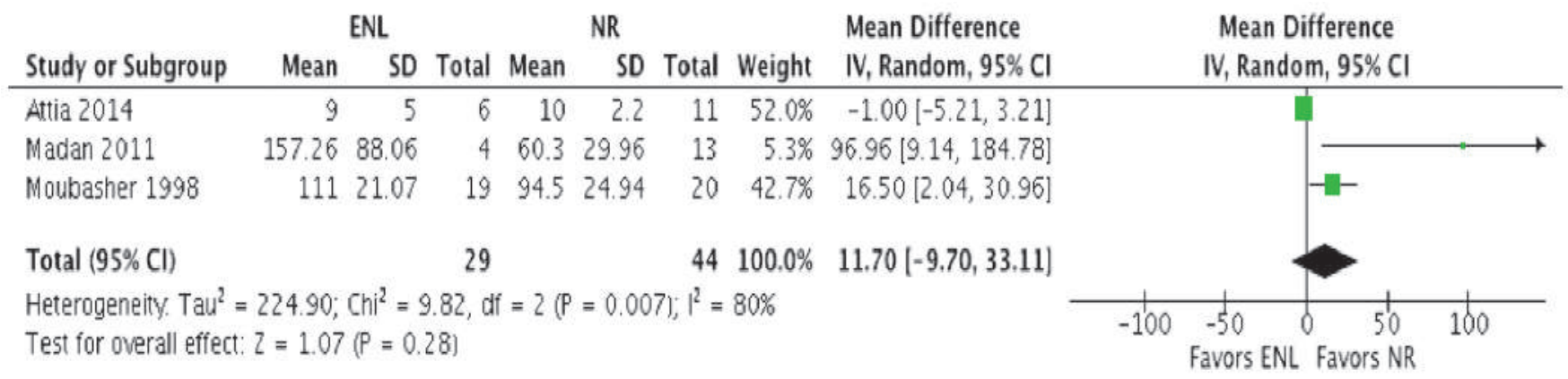

Figure 5. Forest plot for interleukin-10 (IL-10) showing the weighted mean differences (WMDs) and 95\% confidence intervals (Cls) of individual studies and pooled WMDs and $95 \% \mathrm{Cls}$ in patients with erythema nodosum leprosum (ENL) and non-reactional (NR) leprosy using a random-effects model.

\begin{tabular}{|c|c|c|c|c|c|c|c|c|c|c|}
\hline \multirow[b]{2}{*}{ Study or Subgroup } & \multicolumn{3}{|c|}{ ENL } & \multicolumn{3}{|c|}{ NR } & \multicolumn{2}{|r|}{ Mean Difference } & \multirow{2}{*}{$\begin{array}{l}\text { Mean Difference } \\
\text { IV, Random, } 95 \% \mathrm{Cl}\end{array}$} & \\
\hline & Mean & SD & Total & Mean & SD & Total & Weight & IV, Random, $95 \% \mathrm{Cl}$ & & \\
\hline Abdallah 2013 & 20 & 27.8 & 6 & 12.5 & 42.6 & 11 & $30.3 \%$ & $7.50[-26.09,41.09]$ & - & \\
\hline Attia 2014 & 20 & 1.76 & 6 & 12.5 & 19.3 & 11 & $30.9 \%$ & $7.50[-3.99,18.99]$ & + & \\
\hline Chaitanya 2012 & 231.26 & 265.06 & 21 & 207.98 & 260.9 & 6 & $14.7 \%$ & $23.28[-214.28,260.84]$ & & \\
\hline Saini 2016 & 650 & 195,2 & 10 & 45.52 & 22.7 & 10 & $24.0 \%$ & $604.48[482.68,726.28]$ & & ' \\
\hline Total $(95 \% \mathrm{Cl})$ & & & 43 & & & 38 & $100.0 \%$ & $153.19[27.53,278.85]$ & & \\
\hline $\begin{array}{l}\text { Heterogeneity. Tau } \\
\text { Test for overall effect }\end{array}$ & $\begin{array}{l}13253.1 \\
Z=2.39\end{array}$ & $\begin{array}{l}15 ; \mathrm{Ch}^{2}= \\
(\mathrm{P}=0.02\end{array}$ & $\begin{array}{l}91.56 \text {, } \\
\text { 2) }\end{array}$ & $d f=3$ & $<0$. & $01 \% ;$ & $\left.\right|^{2}=97 \%$ & & $\begin{array}{ccc}-200 & -100 & 0 \\
\text { Favors ENL. Favors }\end{array}$ & \\
\hline
\end{tabular}

Figure 6. Forest plot for interleukin-17 (IL-17) showing the weighted mean differences (WMDs) and 95\% confidence intervals (Cls) of individual studies and pooled WMDs and $95 \% \mathrm{Cls}$ in patients with erythema nodosum leprosum (ENL) and non-reactional (NR) leprosy using a random-effects model.

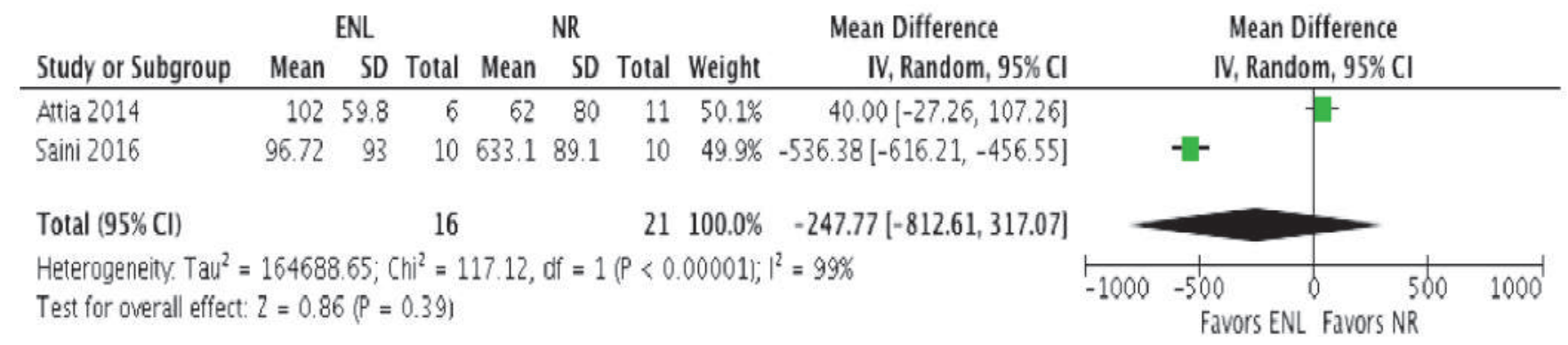

Figure 7. Forest plot for interleukin-22 (IL-22) showing the weighted mean differences (WMDs) and 95\% confidence intervals (Cls) of individual studies and pooled WMDs and $95 \% \mathrm{Cls}$ in patients with erythema nodosum leprosum (ENL) and non-reactional (NR) leprosy using a random-effects model. 


\section{Transforming growth factor- $\beta$}

Combining serum TGF- $\beta$ levels resulted in a nonsignificant weighted mean difference $(-0.08,95 \%$ CI -5.36 $5.21, Z=0.03, p=0.98)$ between patients with ENL and NR leprosy (Figure 8). The studies did not exhibit any heterogeneity, with $\mathrm{I}^{2}$ at $0 \%$ (Figure 9).

\section{Interferon- $\gamma$}

Finally, three studies investigated serum IFN- $\gamma$ levels in ENL versus NR leprosy. The WMD between the 2 groups was 384.06 (95\% CI -79.35-688.76), with an overall $\mathrm{Z}$ score of $2.47(p=0.01)$ indicating a significantly lower level of serum IFN- $\gamma$ in patients with ENL as shown in Figure 10. Heterogeneity among studies was considerable however, with $\mathrm{I}^{2}$ at $97 \%$.

\section{DISCUSSION}

\section{Summary of main results}

From the Ridley-Jopling classification, the lepromatous pole of the leprosy spectrum is characterized by the predominance of $\mathrm{CD} 8+$ (suppressor/cytotoxic) $\mathrm{T}$ cells. This brings about a Th2 cytokine pattern characterized predominantly by the release of cytokines, which have a negative immunoregulatory effect on cell-mediated immunity. ${ }^{3,6}$ The results of this meta-analysis suggest that in comparison to non-reactional leprosy states, erythema nodosum leprosum exhibits a further shift towards this Th2-type response.

Interleukin-17 is a pro-inflammatory cytokine, which acts by recruiting monocytes and neutrophils. It binds

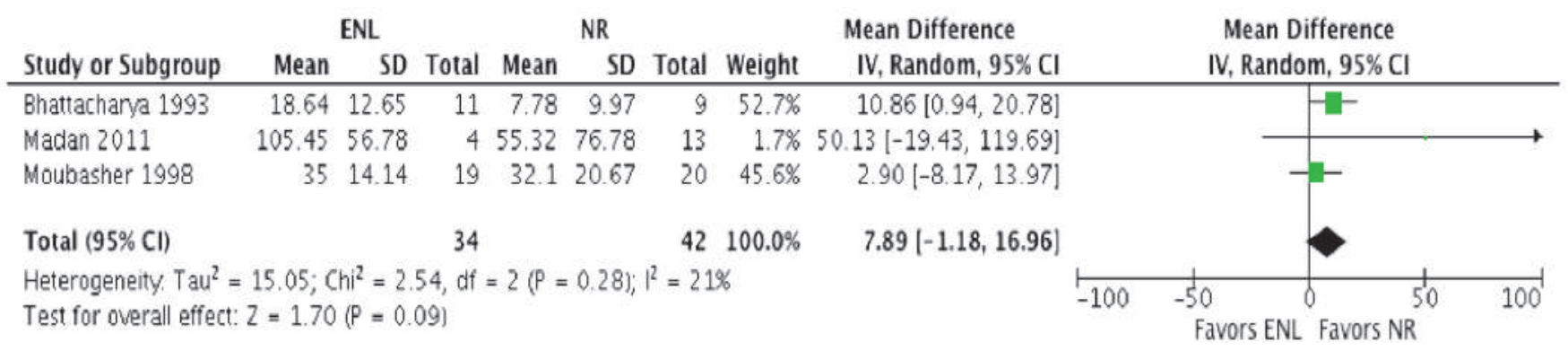

Figure 8. Forest plot for tumor necrosis factor- $\alpha$ (TNF- $\alpha$ ) showing the weighted mean differences (WMDs) and $95 \%$ confidence intervals (Cls) of individual studies and pooled WMDs and $95 \% \mathrm{Cls}$ in patients with erythema nodosum leprosum (ENL) and non-reactional (NR) leprosy using a random-effects model.

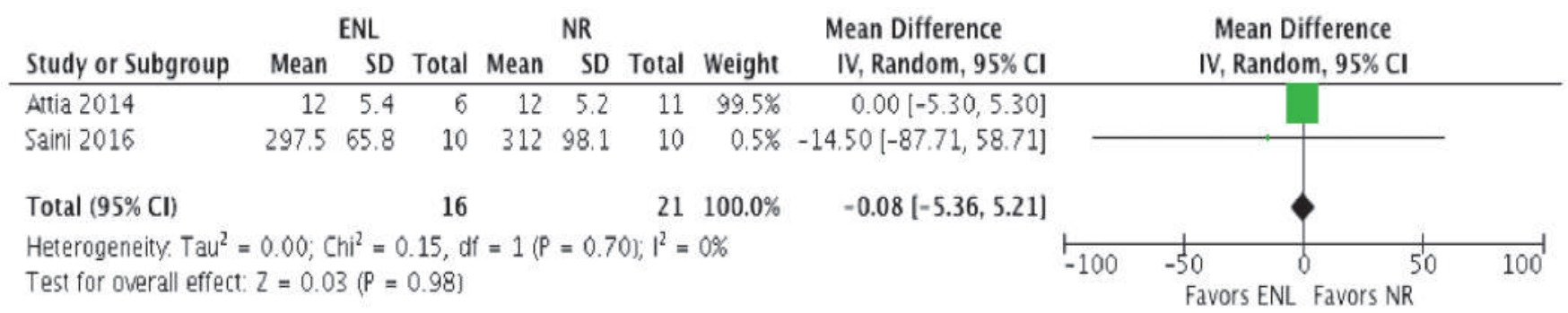

Figure 9. Forest plot for transforming growth factor- $\beta$ (TGF- $\beta$ ) showing the weighted mean differences (WMDs) and 95\% confidence intervals $(\mathrm{Cls})$ of individual studies and pooled WMDs and $95 \% \mathrm{Cls}$ in patients with erythema nodosum leprosum (ENL) and non-reactional (NR) leprosy using a random-effects model.

\begin{tabular}{|c|c|c|c|c|c|c|c|c|c|c|}
\hline \multirow[b]{2}{*}{ Study or Subgroup } & \multicolumn{3}{|c|}{ ENL } & \multicolumn{3}{|c|}{ NR } & \multicolumn{2}{|r|}{ Mean Difference } & \multirow{2}{*}{$\begin{array}{l}\text { Mean Difference } \\
\text { IV, Random, } 95 \% \mathrm{CI}\end{array}$} & \multirow[b]{3}{*}{ I } \\
\hline & Mean & SD & Total & Mean & SD & Total & Weight & IV, Random, $95 \% \mathrm{Cl}$ & & \\
\hline Belgaumkar 2007 & 752 & 1 & 1 & 126.7 & 31.32 & 18 & $34.6 \%$ & $625.30[610.70,639.90]$ & & \\
\hline Madan 2011 & 352.31 & 140.2 & 4 & 55.17 & 62.42 & 13 & $32.2 \%$ & $297.14[155.62,438.66]$ & - - & \\
\hline Moubasher 1998 & 562.5 & 173.68 & 19 & 346 & 180.42 & 20 & $33.1 \%$ & $216.50[105.36,327.64]$ & & \\
\hline Total $(95 \% \mathrm{Cl})$ & & & 24 & & & 51 & $100.0 \%$ & $384.06[79.35,688.76]$ & & \\
\hline \multicolumn{9}{|c|}{$\begin{array}{l}\text { Heterogeneity. Tau }{ }^{2}=69742.26 ; \mathrm{Chi}^{2}=70.68, \mathrm{df}=2(\mathrm{P}<0.00001) ; \mathrm{I}^{2}=97 \% \\
\text { Test for overall effect: } Z=2.47(P=0.01)\end{array}$} & 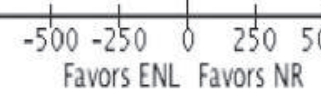 & \\
\hline
\end{tabular}

Figure 10. Forest plot for transforming growth interferon- $\gamma$ (IFN- $\gamma$ ) showing the weighted mean differences (WMDs) and 95\% confidence intervals (Cls) of individual studies and pooled WMDs and $95 \% \mathrm{Cls}$ in patients with erythema nodosum leprosum (ENL) and non-reactional (NR) leprosy using a random-effects model. 
to type I cell surface receptors on T-helper cells, thereby stimulating a Th1 response. ${ }^{36}$ In this study, serum IL-17 of ENL patients showed a significantly lower level compared to non-reactional leprosy. This implies that there is a further decrease in cell-mediated immunity, which could account for a patient's worsening clinical presentation.

Similarly, interferon- $\gamma$ is another pro-inflammatory cytokine and is an important feature of the Th1 response. Following its release from Th1 cells, IFN- $\gamma$ stimulates the production of reactive oxygen species by macrophages, which interfere with the growth of mycobacteria. ${ }^{3}$ From the results of this study, patients with ENL exhibit a significantly lower level of serum IFN- $\gamma$ compared to nonreactional states. Again this suggests a further shift towards a Th2-type response, mirroring that of IL-17.

While non-significant, the trend for other proinflammatory cytokines included in this study such as interleukin- $1 \beta$, interleukin-6, and tumor necrosis factor- $\alpha$ are generally lower in ENL, consistent with the findings for IL-17 and IFN- $\gamma$. In contrast, the results for the antiinflammatory cytokine interleukin-10 and interleukin-22 are conflicting. Based on the results of this meta-analysis, IL-10 appears to be higher in non-reactional leprosy, while IL-22 is higher in ENL though the results are again, nonsignificant. Finally, transforming growth factor- $\beta$, another pro-inflammatory cytokine appears to have similar levels in both ENL and NR groups, though the results are nonsignificant.

\section{Agreement and disagreement with other studies or reviews}

To date, no other published meta-analyses investigating the serum cytokine profiles in ENL compared to nonreactional states have been found.

Similar to the results of this meta-analysis, a previous study by Goulart et al. in 2000 measuring cytokine production of peripheral blood mononuclear cells (PBMCs) showed a Th2-type response occurring in ENL. ${ }^{37}$ In contrast, other studies done by Moraes et al. (1999) and Teles et al. (2002) investigating mRNA expression in reactional lesions have found significantly higher levels of the proinflammatory cytokines TNF- $\alpha$ and IL-6..$^{38,39}$ This is similar to the results of the study done by Barnes et al. (1992) with PBMCs wherein the release of TNF- $\alpha$ was found to be highest in patients with ENL. ${ }^{27}$ These findings support the utility of thalidomide in the treatment of ENL as it inhibits the production of TNF- $\alpha$. Other studies investigating IFN- $\gamma$ mRNA expression also found higher levels in ENL compared to non-reactional states..$^{40,41}$

\section{Strengths and limitations}

This is the first meta-analysis to determine the serum cytokine profile of erythema nodosum leprosum compared to non-reactional states of leprosy, pooling the results of a total of 8 cross-sectional studies, with a total of 197 participants. We performed an extensive open literature search using five different databases to be able to retrieve all relevant articles, and investigated both pro-inflammatory and anti-inflammatory markers implicated in ENL. The results of this investigation may contribute to further understanding the immunologic mechanisms governing erythema nodosum leprosum.

All studies included in this meta-analysis were single institutional cross-sectional studies, which may have an inherent selection bias. The sample sizes of the individual studies were small, which may account for the high degree heterogeneity between data sets. The effects of other confounding factors such as bacterial load and age could not be analyzed due to the unavailability of data. In addition, publication bias could not be assessed since the aggregate number of studies was less than ten.

\section{CONCLUSION}

\section{Implication for practice}

The results of the meta-analysis suggest that ENL is an exacerbation of the Th2 cytokine response seen in the lepromatous pole of leprosy, showing a significant decrease in the pro-inflammatory cytokines IL-17 and IFN- $\gamma$. This suggests that therapies which aim to reverse the decline in IL-17 and IFN- $\gamma$ cytokine levels may also result in a reversal of its clinical manifestations. While there are no known therapies used to augment IL-17 levels, interferon gamma therapy used in the treatment of chronic granulomatous diseases and osteoporosis may provide clinical benefit for patients with ENL.

\section{Implication for research}

The 8 cross-sectional studies included in this review had small sample sizes and incomplete data for subgroup analyses. Thus, there is a need for good quality studies involving larger sample sizes to be able to draw more robust conclusions. In addition, other cytokines may also be investigated to be able to provide a more comprehensive cytokine profile in ENL. Confounding factors such as age and bacterial index should be explored and its effect on cytokine levels in ENL should be clarified. In addition, other meta-analyses involving the levels of cytokine mRNA or gene expression in ENL may provide a clearer picture of the pathogenesis of ENL and may be used to corroborate the findings of this investigation.

\section{Disclaimer}

The views expressed in this article are the authors' own and do not reflect the views of the institution.

\section{Statement of Authorship}

All authors approved the final version submitted.

\section{Author Disclosure}

All authors declared no conflict of interest. 


\section{Funding Source}

This paper was funded by the authors. No external funding agency.

\section{REFERENCES}

1. Walker SL, Lockwood DNJ. The clinical and immunological features of leprosy. Br Med Bull. 2006;77-8(1):103-121. doi:10.1093/ $\mathrm{bmb} / \mathrm{ld} 1010$.

2. World Health Organization. Expert Committee on Leprosy. Eigth Report. World Health Organ Tech Rep Ser. 2012;(968):1-61.

3. Modlin RL. Th1-Th2 paradigm: insights from leprosy. J Invest Dermatol. 1994;102(6):828-32.

4. Ridley DS, Jopling WH. Classification of leprosy according to immunity. A five-group system. Int J Lepr Other Mycobact Dis. 34(3):255-73.

5. Van Veen NH, Lockwood DN, van Brakel WH, Ramirez Jr J, Richardus $\mathrm{JH}$. Interventions for erythema nodosum leprosum. In: Van Veen NH, ed. Cochrane Database of Systematic Reviews. Chichester, UK: John Wiley \& Sons, Ltd; 2009. doi:10.1002/14651858.CD006949.pub2

6. Rea TH. St. John Dermatological Society Oration, 1994. Immune responses in leprosy, cytokines and new archetypes for dermatology. Clin Exp Dermatol. 1995;20(2):89-97.

7. Saini C, Siddiqui A, Ramesh V, Nath I. Leprosy Reactions Show Increased Th17 Cell Activity and Reduced FOXP3+ Tregs with Concomitant Decrease in TGF- $\beta$ and Increase in IL-6. Johnson C, ed. PLoS Neg1 Trop Dis. 2016;10(4):e0004592. doi:10.1371/journal. pntd.0004592

8. Zhou L, Chong MMW, Littman DR. Plasticity of CD4+ T Cell Lineage Differentiation. Immunity. 2009;30(5):646-55. doi:10.1016/j. immuni.2009.05.001

9. Nath I, Saini C, Valluri VL. Immunology of leprosy and diagnostic challenges. Clin Dermatol. 2015;33(1):90-8. doi:10.1016/j. clindermatol.2014.07.005

10. Manandhar R, LeMaster JW, Roche PW. Risk factors for erythema nodosum leprosum. Int J Lepr Other Mycobact Dis. 1999;67(3):270-8.

11. Ridley DS. 6 - The Leprosy Bacillus BT - Pathogenesis of Leprosy and Related Diseases.1988. doi:http://dx.doi.org/10.1016/B978-0-72361031-1.50011-4

12. Wells GA, Shea B, O'Connell D, Peterson J, Welch V, Losos M TP. The Newcastle-Ottawa Scale (NOS) for assessing the quality of nonrandomised studies in meta-analyses [Internet]. 2014 [cited 2016 December]. Available from http://www.ohri.ca/programs/clinical_ epidemiology/oxford.asp. Published 2014.

13. Higgins JP, Green S. Cochrane Handbook for Systematic Reviews of Interventions Cochrane Book Series THE COCHRANE COLLABORATION ${ }^{\circledR}$; 2011.

14. Moubasher AD, Kamel NA, Zedan H, Raheem DD. Cytokines in leprosy, I. Serum cytokine profile in leprosy. Int J Dermatol. 1998;37(10):733-740.15. Madan NK, Agarwal K, Chander R. Serum cytokine profile in leprosy and its correlation with clinicohistopathological profile. Lepr Rev. 2011;82(4):371-82.

16. Belgaumkar VA, Gokhale NR, Mahajan PM, Bharadwaj R, Pandit DP, Deshpande S. Circulating cytokine profiles in leprosy patients. Lepr Rev. 2007;78(3):223-30.17. Attia EAS, Abdallah M, El-Khateeb E, et al. Serum Th17 cytokines in leprosy: correlation with circulating CD4+ CD25highFoxP3+ T-regs cells, as well as down regulatory cytokines. Arch Dermatol Res. 2014;306(9):793-801. doi:10.1007/s00403-0141486-2.

18. Chaitanya S, Lavania M, Turankar RP, Karri SR, Sengupta U. Increased serum circulatory levels of interleukin $17 \mathrm{~F}$ in type 1 reactions of leprosy. J Clin Immunol. 2012;32(6):1415-20. doi:10.1007/s10875012-9747-3.

19. Abdallah M, Emam H, Attia E, Hussein J, Mohamed N. Estimation of serum level of interleukin-17 and interleukin-4 in leprosy, towards more understanding of leprosy immunopathogenesis. Indian J Dermatol Venereol Leprol. 2013;79(6):772-6. doi:10.4103/03786323.120723
20. Bhattacharya SN, Chattopadhaya D, Saha K. Tumor necrosis factor: status in reactions in leprosy before and after treatment. Int J Dermatol. 1993;32(6):436-9.

21. Sampaio EP, Kaplan G, Miranda A, et al. The influence of thalidomide on the clinical and immunologic manifestation of erythema nodosum leprosum. J Infect Dis. 1993;168(2):408-14.

22. Vieira LM, Sampaio EP, Nery JA, et al. Immunological status of ENL (erythema nodosum leprosum) patients: its relationship to bacterial load and levels of circulating IL-2R. Rev Inst Med Trop Sao Paulo. 38(2):103-11. 23. Sreenivasan P, Misra RS, Wilfred D, Nath I. Lepromatous leprosy patients show $\mathrm{T}$ helper 1-like cytokine profile with differential expression of interleukin-10 during type 1 and 2 reactions. Immunology. 1998;95(4):529-36.

24. Sampaio EP, Moraes MO, Nery JA, Santos AR, Matos HC, Sarno EN. Pentoxifylline decreases in vivo and in vitro tumour necrosis factor-alpha (TNF-alpha) production in lepromatous leprosy patients with erythema nodosum leprosum (ENL). Clin Exp Immunol. 1998;111(2):300-8.

25. Jadhav R, Suneetha L, Kamble R, et al. Analysis of Antibody and Cytokine Markers for Leprosy Nerve Damage and Reactions in the INFIR Cohort in India. Small PLC, ed. PLoS Negl Trop Dis. 2011;5(3):e977. doi:10.1371/journal.pntd.0000977

26. De Simone C, Caldarola G, Scaldaferri F, et al. Clinical, histopathological, and immunological evaluation of a series of patients with erythema nodosum. Int J Dermatol. 2016;55(5):e289-94. doi:10.1111/ijd.13212

27. Barnes PF, Chatterjee D, Brennan PJ, Rea TH, Modlin RL. Tumor necrosis factor production in patients with leprosy. Infect Immun. 1992;60(4):1441-6.28. Parida SK, Grau GE, Zaheer SA, Mukherjee R. Serum tumor necrosis factor and interleukin 1 in leprosy and during lepra reactions. Clin Immunol Immunopathol. 1992;63(1):23-7.

29. Partida-Sanchez S, Favila-Castillo L, Pedraza-Sanchez S, et al. IgG antibody subclasses, tumor necrosis factor and IFN-gamma levels in patients with type II lepra reaction on thalidomide treatment. Int Arch Allergy Immunol. 1998;116(1):60-6.

30. Iyer A, Hatta M, Usman R, et al. Serum levels of interferon- $\gamma$, tumour necrosis factor- $\alpha$, soluble interleukin-6R and soluble cell activation markers for monitoring response to treatment of leprosy reactions. Clin Exp Immunol. 2007;150(2):210-6. doi:10.1111/j.13652249.2007.03485.x

31. Modlin RL, Mehra V, Jordan R, Bloom BR, Rea TH. In situ and in vitro characterization of the cellular immune response in erythema nodosum leprosum. J Immunol. 1986;136(3):883-6.

32. Sarno EN, Grau GE, Vieira LM, Nery JA. Serum levels of tumour necrosis factor-alpha and interleukin-1 beta during leprosy reactional states. Clin Exp Immunol. 1991;84(1):103-8.

33. Munk ME, Anding P, Schettini AP, Cunha MG, Kaufmann SH. Soluble tumor necrosis factor alpha receptors in sera from leprosy patients. Infect Immun. 1999;67(1):423-5.

34. Stefani MM, Guerra JG, Sousa ALM, et al. Potential plasma markers of type 1 and type 2 leprosy reactions: a preliminary report. BMC Infect Dis. 2009;9(1):75. doi:10.1186/1471-2334-9-75

35. Abdallah M, Attia EAS, Saad AA, et al. Serum Th1/Th2 and macrophage lineage cytokines in leprosy; correlation with circulating CD4(+) CD25(high) FoxP3(+) T-regs cells. Exp Dermatol. 2014;23(10):742-7. doi:10.1111/exd.12529

36. Miossec P. IL-17 and Th17 cells in human inflammatory diseases. Microbes Infect. 2009;11(5):625-30. doi:10.1016/j.micinf.2009.04.003

37. Goulart IM, Mineo JR, Foss NT. Production of transforming growth factor-beta 1 (TGF-beta1) by blood monocytes from patients with different clinical forms of leprosy. Clin Exp Immunol. 2000;122(3):330-4.

38. Moraes MO, Sarno EN, Almeida AS, et al. Cytokine mRNA expression in leprosy: a possible role for interferon-gamma and interleukin-12 in reactions (RR and ENL). Scand J Immunol. 1999;50(5):541-9.

39. Teles RMB, Moraes MO, Geraldo NTR, Salles AM, Sarno EN, Sampaio EP. Differential TNFalpha mRNA regulation detected in the epidermis of leprosy patients. Arch Dermatol Res. 2002;294(8):35562. doi:10.1007/s00403-002-0340-0. 
40. Cooper CL, Mueller C, Sinchaisri TA, et al. Analysis of naturally occurring delayed-type hypersensitivity reactions in leprosy by in situ hybridization. J Exp Med. 1989;169(5):1565-81.
41. Kahawita IP, Lockwood DNJ. Towards understanding the pathology of erythema nodosum leprosum. Trans R Soc Trop Med Hyg. 2008;102(4):329-37. doi:10.1016/j.trstmh.2008.01.004.

Appendix A. Standard data extraction form

\begin{tabular}{|c|c|c|c|c|c|c|c|c|c|c|c|}
\hline \multirow[b]{2}{*}{ Author } & \multirow[b]{2}{*}{ Year } & \multirow[b]{2}{*}{ Study Design } & \multirow[b]{2}{*}{ Country } & \multicolumn{3}{|c|}{ ENL } & \multicolumn{3}{|c|}{ NR } & \multirow[b]{2}{*}{ Cytokines } & \multirow[b]{2}{*}{ Method } \\
\hline & & & & $\mathbf{N}$ & $\begin{array}{l}\text { Mean age } \\
\text { (years) }\end{array}$ & $\begin{array}{l}\text { Male, } \\
\%\end{array}$ & $\mathbf{N}$ & $\begin{array}{l}\text { Mean age } \\
\text { (years) }\end{array}$ & $\begin{array}{l}\text { Male, } \\
\%\end{array}$ & & \\
\hline Bhattacharya & 1993 & Cross-sectional & India & 11 & - & - & 9 & - & - & TNF-a & ELISA \\
\hline Moubasher & 1998 & Cross-sectional & Egypt & 19 & - & - & 20 & - & - & $\begin{array}{l}\text { IL-1 } \beta, \text { IL-10, } \\
\text { TNF- } \alpha, \text { IFN- } \gamma\end{array}$ & ELISA \\
\hline Belgaumkar & 2007 & Cross-sectional & India & 1 & - & - & 18 & - & - & IL-6, IFN- $\gamma$ & ELISA \\
\hline Madan & 2011 & Cross-sectional & India & 4 & - & - & 13 & - & - & $\begin{array}{l}\text { IL-1 } \beta \text {, IL-10, } \\
\text { TNF- } \alpha, \text { IFN- } \gamma\end{array}$ & ELISA \\
\hline Chaitanya & 2012 & Cross-sectional & India & 21 & 34.8 & 86 & 10 & - & - & IL-17 & ELISA \\
\hline Abdallah & 2013 & Cross-sectional & Egypt & 6 & - & - & 11 & - & - & IL-4, IL-17 & ELISA \\
\hline Attia & 2014 & Cross-sectional & Egypt & 6 & - & - & 11 & - & - & $\begin{array}{l}\text { IL-10, IL-17, } \\
\text { IL-22, TGF- } \beta\end{array}$ & ELISA \\
\hline Abdallah & 2014 & Cross-sectional & Egypt & 6 & - & - & 11 & - & - & $\mathrm{IL}-4$ & ELISA \\
\hline Saini & 2016 & Cross-sectional & India & 10 & 41 & 73 & 10 & 42 & 67 & $\begin{array}{l}\text { IL-1 } \beta, \text { IL-6, IL-17, } \\
\text { IL-22, TGF- } \beta\end{array}$ & ELISA \\
\hline Total & & & & 84 & & & 113 & & & & \\
\hline
\end{tabular}

\section{Have you read the current trends in}

Medical and Health Research in the Philippines?

\section{Acta Medica Philippina The National Health Science Journal}

Access Online: www.actamedicaphilippina.org 